HNF-SP-0842

Revision 2

\title{
222-S Laboratory Maintenance Implementation Plan
}

\author{
J. L. Heinemann
}

L. F. Perkins

Waste Management Federal Services of Hanford, Inc.

Date Published

August 1997

Prepared for the U.S. Department of Energy

Assistant Secretary for Environmental Management

Project Hanford Management Contractor for the

U.S. Department of Energy under Contract DE-AC06-96RL13200

Approved for public release; distribution is unlimited 


\section{RELEASE AUTHORIZATION}

Document Number: HNF-SP-0842, Rev. 2

Document Title: $\quad 222-5$ Laboratory Maintenance Implementation P1an

Release Date: $\quad 8 / 13 / 97$

This document was reviewed following the procedures described in WHC-CM-3-4 and is:

APPROVED FOR PUBLIC RELEASE

WHC Information Release Administration Specialist:

August 13, 1997

Kara M. Broz 
WASTE MANAGEMENT FEDERAL SERVICES OF HANFORD

P. O. BOX 700

Richland, Washington 99352-0700

\section{HNF-SP-0842}

Revision 2

\section{2-S LABORATORY}

\section{MAINTENANCE IMPLEMENTATION PLAN}




\section{APPROVALS}

Prepared By:
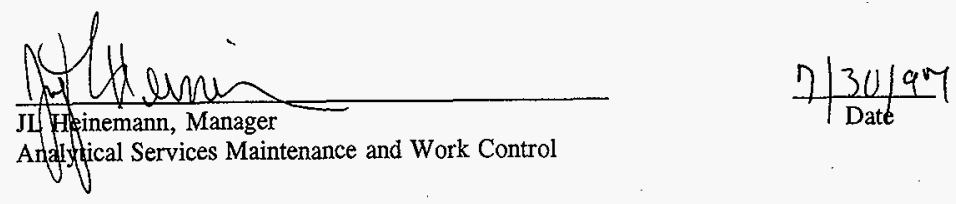

Approved By:
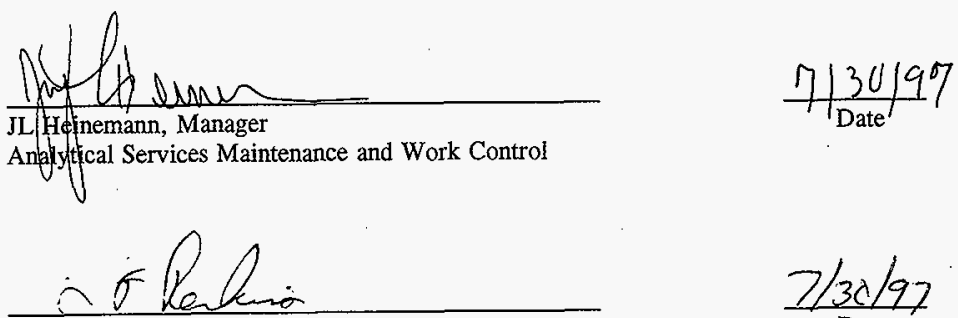

LF Perkins, Manager

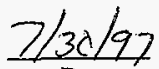

222-S Laboratory 


\section{FOREWORD}

This Maintenance Improvement Plan is written to satisfy the requirements of DOE Order 4330.4B, "MAINTENANCE MANAGEMENT PROGRAM", that specifies the general policy and objectives for the establishment of DOE controlled maintenance programs. These programs provide for the management and performance of cost-effective maintenance and repair of Department of Energy (DOE) property, which includes facilities.

A review of DOE Order $4330.4 \mathrm{~B}$, particularly Chapter II the nuclear portion, against existing WMH site programs and policies has provided assurance that most requirements of this order have already been implemented by existing WMH programs. Most requirements and applicable guidelines of $4330.4 \mathrm{~B}$ that are deficient or not implemented are presently being developed and implemented through WMH site policies and programs. Where no program is presently identified or being developed for $4330.4 \mathrm{~B}$ requirements, responsibility for implementation has been assigned within this plan.

In order to implement the requirements specified, this order requires a Maintenance Management Plan be developed for each new DOE controlled facility where maintenance is contractually the responsibility of DOE and where Federal funds are used totally or in part. In developing a maintenance plan for the 222-S Laboratory a number of evaluations have been performed and the results considered for implementation. A maintainability study is performed for ergonomic and ALARA considerations of maintenance activities to maximize the accessibility of equipment and components for maintenance and minimize radiation exposure. Through a concerted maintainability design review of 222-S Laboratory, an efficient and cost effective maintenance program has been implemented. 


\section{TABLE OF CONTENTS}

1.0 EXECUTIVE SUMMARY $\ldots \ldots \ldots \ldots \ldots \ldots \ldots \ldots \ldots \ldots \ldots \ldots$

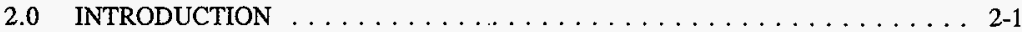

$2.1 \quad$ Facility Complex Description . . . . . . . . . . . . . 2-1

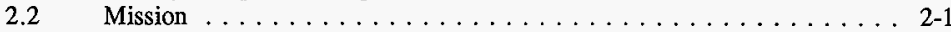

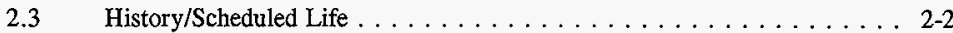

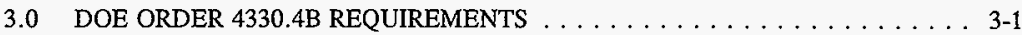

3.1 Maintenance Management Program Scope . . . . . . . . . . 3-1

3.2 Maintenance Program Requirements . . . . . . . . . . . . 3-1

3.3 Graded Approach Strategy $\ldots \ldots \ldots \ldots \ldots \ldots \ldots \ldots \ldots \ldots . \ldots \ldots$ 3-2

3.3.1 Overall Strategy and Basis . . . . . . . . . . . 3-3

3.3.2 Strategy for Safety Related Items . . . . . . . . . . . 3-3

4.0 DOE ORDER 4330.4B CHAPTER II REQUIREMENTS . . . . . . . . . . . . 4-1

4.1 Evaluation of Compliance Elements . . . . . . . . . . . . 4-1

4.2 Maintenance Organization and Administration $\ldots \ldots \ldots \ldots \ldots$ 4-1

4.2.1 Maintenance Organization Policies . . . . . . . . . 4-1

4.2.2 Maintenance Strategy . . . . . . . . . . . . . . 4-1

Working Relationships $\ldots \ldots \ldots \ldots \ldots \ldots \ldots$ 4-1

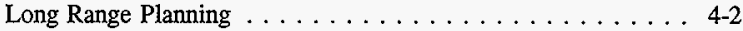

4.2.3 Staffing Resources . . . . . . . . . . . . . . 4-2

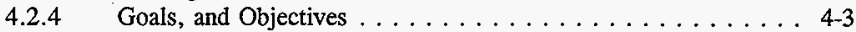

4.2.5 Accountability . . . . . . . . . . . . . . . 4-3

4.3 Training and Qualification $\ldots \ldots \ldots \ldots \ldots \ldots \ldots \ldots \ldots \ldots$

4.3 .1 Responsibilities .................. 4-4

4.3.2 Maintenance Training Programs $\ldots \ldots \ldots \ldots \ldots \ldots .44$

4.3.3 Training Schedules and Support . . . . . . . . . . 4-4

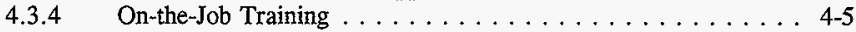

4.3.5 Qualifications .................... 4-5

4.3.6 Training in Root Cause Analysis . . . . . . . . . . 4-5

4.3.7 Training Program Approval, Effectiveness, and Feedback . . . 4 4-5

4.3.8 Management and Supervisory Training . . . . . . . . 4-6

4.4 Maintenance Facilities, Equipment, and Tools $\ldots \ldots \ldots \ldots \ldots$. $\ldots$.6

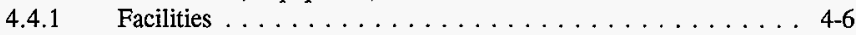

Shops and Satellite Work Areas . . . . . . . . . . 4-6

Lay-down and Staging Area $\ldots \ldots \ldots \ldots \ldots \ldots \ldots .4 .7$

Storage Facilities . . . . . . . . . . . . . . . 4-7

Temporary Facilities $\ldots \ldots \ldots \ldots \ldots \ldots \ldots$. 4-7

Decontamination Facilities . . . . . . . . . . . . . . 4 4-7

4.4.2 Tool and Equipment Storage . . . . . . . . . . . . . 4-7

4.4 .3 Office Equipment $\ldots \ldots \ldots \ldots \ldots \ldots \ldots \ldots .4 .8$ 


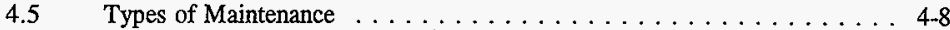

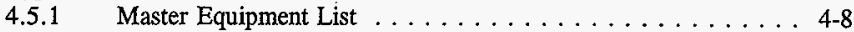

4.5.2 Types of Maintenance . . . . . . . . . . . . . . 4.8 4.8

Corrective Maintenance . . . . . . . . . . . . . . . 4-8

Preventive Maintenance $\ldots \ldots \ldots \ldots$. . . . . . . . . 4-9

Predictive Maintenance . . . . . . . . . . . . . . . . 4-9

4.5.3 Maintenance Action and Frequency Selection . . . . . . 4-10

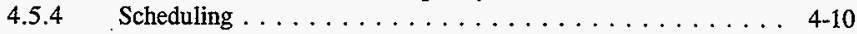

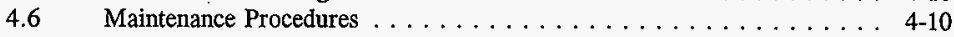

4.6.1 Procedure Development and Writing . . . . . . . . . . . 4 4-11

4.6.2 Procedure Verification $\ldots \ldots \ldots \ldots \ldots \ldots \ldots \ldots$ 4-11

4.6.3 Procedure Validation . . . . . . . . . . . . . . 4 4-11

4.6.4 Procedure Approval . . . . . . . . . . . . . . . . 4 4-12

4.6.5 Procedure Use . . . . . . . . . . . . . . . 4-12

4.7 Planning, Scheduling, and Coordination of Maintenance $\ldots \ldots \ldots \ldots 4-12$

4.7.1 Planning for Maintenance Activities $\ldots \ldots \ldots \ldots \ldots \ldots$ 4-12

Planning Group Organization $\ldots \ldots \ldots \ldots \ldots \ldots \ldots$ 4-13

Planning Group Responsibilities . . . . . . . . . . 4-13

4.7.2 Scheduling Maintenance Activities . . . . . . . . . . 4-13

Control of Work Backlog . . . . . . . . . . . 4 4-13

Work Priority . . . . . . . . . . . . . . 4-13

4.7.3 Coordination of Maintenance Activities . . . . . . . . . . 4-14

4.7.4 Outage Planning, Scheduling, and Coordination . . . . . . . 4 4-14

4.8. Control of Maintenance Activities . . . . . . . . . . . . . 4-14

4.8.1 Work Control Procedure . . . . . . . . . . . 4-14

4.8.2 Work Request . . . . . . . . . . . . . . 4-15

4.8.3 Supervision of Maintenance Activities . . . . . . . . . 4-15

4.8.4 Review of Completed Work Requests . . . . . . . . . 4-15

4.8.5 Temporary Repairs . . . . . . . . . . . . . . . 4 4-16

4.8.6 Control of Nonfacility Contractor and Subcontractor Personnel 4-16

4.9 Post-Maintenance Testing $\ldots \ldots \ldots \ldots \ldots \ldots \ldots \ldots \ldots$. 4 .16

4.9.1 Post-Maintenance Test Requirements . . . . . . . . . . 4-16

4.9.2 Post-Maintenance Test Program Scope . . . . . . . . . . . 4-17

4.9.3 Post-Maintenance Test Control . . . . . . . . . . . 4-17

4.9.4 Post-Maintenance Test Performance Documentation, and

Acceptance . . . . . . . . . . . . . . . 4-17

4.10 Procurement of Parts, Materials, and Services . . . . . . . . 4-17

4.10.1 Procurement Policy and Procedures $\ldots \ldots \ldots \ldots \ldots \ldots$ 4-18

4.10 .2 Procurement Initiation $\ldots \ldots \ldots \ldots \ldots \ldots \ldots \ldots$ 4-18

4.10.3 Procurement Control . . . . . . . . . . . . . . 4-18

4.10.4 Services . . . . . . . . . . . . . . . 4-19

4.11 Material Receipt, Inspection, Handling, Storage, Retrieval, and Issuance . 4-19

4.11.1 Receipt and Inspection . . . . . . . . . . . . . . . . 4-19

4.11 .2 Handling . . . . . . . . . . . . . . . 40

4.11.3 Storage Material and Equipment . . . . . . . . . 4 4-20

4.11.4 Retrieval and Issuance $\ldots \ldots \ldots \ldots \ldots \ldots \ldots . .4 .21$ 
4.12 Control and Calibration of Measuring and Test Equipment . . . . . . 4-21

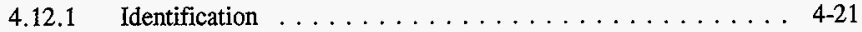

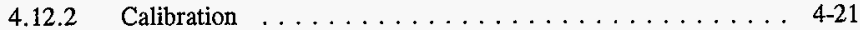

Calibration Standards . . . . . . . . . . . . . . 4 4-21

Calibration Procedures . . . . . . . . . . . . . . 4-22

Calibration Frequency $\ldots \ldots \ldots \ldots \ldots$. . . . . . . . . . . . . . . . . . . .

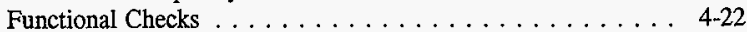

4.12 .3 Control ........................ 4 $4 \ldots \ldots \ldots$

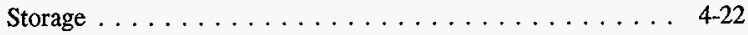

Uncalibrated M\&TE . . . . . . . . . . . . . 4-23

M\&TE with Limited Use . . . . . . . . . . . . . . . 4 4-23

Issue and Recall . . . . . . . . . . . . . . . . 4-23

Contaminated M\&TE . . . . . . . . . . . . . . 4-23

4.12 .4 Evaluation . . . . . . . . . . . . . . . . . 4-23

Out-of-Calibration and Defective M\&TE . . . . . . . . 4-23

Performance Trending ............... 4-23

4.13 Maintenance Tools and Equipment Control ... . . . . . . . . . 4-24

4.13.1 Storage and Issuance . . . . . . . . . . . . . . . . 4-24

4.13.2 Tool and Equipment Maintenance . . . . . . . . . . . . . 4-24

4.13.3 Use of Special Tools and Equipment . . . . . . . . . . . . . . 4-24

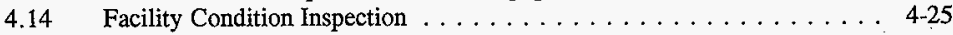

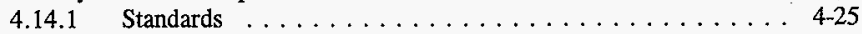

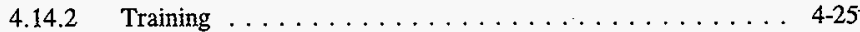

4.14 .3 Procedures . . . . . . . . . . . . . . . . 4 4 4 . 26

4.14 .4 Scope of Inspections . . . . . . . . . . . . . . 4 4 . . . . . . . . .

4.14 .5 Inspection Program Elements . . . . . . . . . . . . 4-26 . . . . . . .

4.14 .6 Reporting Deficiencies . . . . . . . . . . . . 4 4 . . . . . . .

4.14.7 Deficiency Follow-up . . . . . . . . . . . . . . . . 4 4 . . . . . . . . . .

4.15 Management Involvement . . . . . . . . . . . . . 4 4-27

4.15.1 Management Involvement . . . . . . . . . . . . . 4-28

4.15.2 Performance Indicators, Goals, and Objective Results . . . . . 4-28

4.15 .3 Feedback . . . . . . . . . . . . . . . . . 4-29

4.15.4 Program Reviews : . . . . . . . . . . . . . 4 4-29

Assessment of Facility Condition and Worker Practices During

Maintenance .................. . . 4-29 . . . . . . .

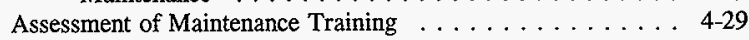

Assessment of Procurement Activities . . . . . . . . . 4-30

Assessment of Measuring and Test Equipment . . . . . . 4-30

4.16 Maintenance History . . . . . . . . . . . . . . . . $4-30$

4.16.1 Program Development ... . . . . . . . . . . . 4-30

Equipment Identification . . . . . . . . . . . . . . 4-30

Data Identification . . . . . . . . . . . . . . . . . . 4 4-30

4.16.2 Data Collection . . . . . . . . . . . . . . . 4-30

4.16.3 Program Use . . . . . . . . . . . . . . . . 4-31

4.17 Analysis of Maintenance Problems ... . . . . . . . . . 4-31

4.17 .1 Information Collection . . . . . . . . . . . 4-31 
4.17.2 Event Analysis . . . . . . . . . . . . . . . . 4-31

4.17.3 Cause Determination $\ldots \ldots \ldots \ldots \ldots \ldots \ldots \ldots$ 4 .32

4.17.4 Corrective Action ................. 4-32

4.17.5 Corrective Action Follow-up $\ldots \ldots \ldots \ldots \ldots \ldots \ldots \ldots$ 4-32

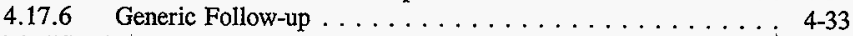

4.18 Modification Work $\ldots \ldots \ldots \ldots \ldots \ldots \ldots \ldots \ldots \ldots, 4-33$

4.18.1 Maintenance Program Interface with Modifications . . . . . . 4-33

4.18.2 Temporary Repairs or Temporary Modifications . . . . . . 4 4-33

4.19 Additional Maintenance Management Requirements . . . . . . . . . 4.34

4.19.1 Seasonal Facility Preservation Requirements . . . . . . . . 4 4-34

5.0 DEVIATIONS REQUESTED WITH SUPPORTING RATIONALE $\ldots \ldots \ldots$ 5-1

6.0 IMPLEMENTATION SCHEDULE $\ldots \ldots \ldots \ldots \ldots \ldots \ldots \ldots \ldots \ldots .1$

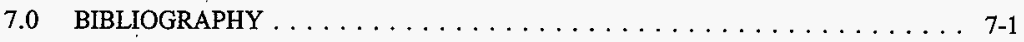




\section{LIST OF TERMS}
$\begin{array}{ll}\text { ALARA } & \text { As Low As Reasonably Achievable } \\ \text { CBRS } & \text { Component Based Recall System }\end{array}$
CERCLA Comprehensive Environmental Response, Compensation, and Liability Act
DOE Department of Energy
EASF Environmental Archive Storage Facility
EDRTS Environmental Data Remedial Tracking System
EPA Environmental Protection Agency
JCS Job Control System
LAN Local Area Network
M\&TE Measuring and Test Equipment
MEL Master Equipment List
MIP Maintenance Implementation Plan
MLSF Mobile Laboratory Storage Facility
OJT On-the-Job Training
PM Preventive Maintenance
RCRA Resource Conservation and Recovery Act
RSME Recall Systems Maintenance Engineering Environmental Archive Facility
SAR Safety Analysis Report
SEL Safety Equipment List
WHC Westinghouse Hanford Company 


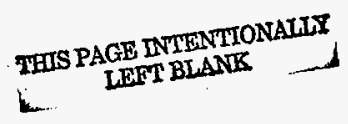




\subsection{EXECUTIVE SUMMARY}

This Maintenance Improvement Plan has been developed for maintenance functions associated with the 222-S Laboratory. This plan is developed from the guidelines presented by Department of Energy (DOE) Order 4330.4B, Maintenance Management Program (DOE 1994), Chapter II.

The objective of this plan is to provide information for establishing and identifying WMH conformance programs and policies applicable to implementation of DOE Order 4330.4B guidelines. In addition, this maintenance plan identifies the actions necessary to develop a costeffective and efficient maintenance program at 222-S Laboratory.

Maintenance activities are mainly going to be performed by existing maintenance organizations within Waste Management Federal Services of Hanford (WMH). Most maintenance performed at 222-S Laboratory is performed by the 222-S Laboratory maintenance organization.

This 222-S Laboratory Maintenance Implementation Plan provides the interface requirements and responsibilities as they apply specifically to $222-S$ Laboratory. This document provides an implementation schedule which has been developed for items considered to be deficient or in need of improvement.

The discussion section as applied to 222-S Laboratory implementation has been developed from a review of programs and practices utilizing the graded approach. Biennial review and additional reviews are conducted as significant programmatic and mission changes are made. This document is revised as necessary to keep this document current and in compliance with DOE requirements. 
THIS PAGE INTENTIONALLY

b.

LEFT BLANK

. 


\subsection{INTRODUCTION}

\subsection{Facility Complex Description}

The 222-S Laboratory is a two-story building 352 feet long and 107 feet wide, located in the southeast corner of the 200 West Area of the Hanford Site, approximately 28 miles north of Richland, Washington. The structure, with a subterranean service level, has laboratory support spaces, office spaces, a multicurie wing, and supplemental service areas. The building is designed with its own waste disposal facility, decontamination facility, fire protection and alarm system, ventilation system, and radiation monitoring system.

The auxiliary buildings are used for storage, offices, and material transfers. The storage facilities contain bulk hazardous materials which are used for laboratory operations. The office buildings house the administrative and technical personnel responsible for the operation of the 222-S Laboratory. The transfer facility is used for receiving hazardous and radioactive waste from the 222-S Laboratory and to transfer the laboratory waste to storage facilities. Auxiliary buildings include the 2716-S Storage Building, an annex which houses the maintenance shop and instrument shop, the 222-SA Laboratory for nonradioactive standards, the 207-SL Retention Basin for potentially radioactive or hazardous liquids, 222-SB Building housing filtration assembly and fans, 222-SC which houses equipment for filtering supply air, and the 219-S Waste Handling Facility.

\subsection{Mission}

The primary mission of the 222-S Laboratories since completion of construction in the early 1950 's remains unchanged in overall scope. The Laboratory provides analytical chemical analysis to Waste Management, Environmental Restoration, Chemical Processing, Environmental Programs, and high level waste characterization. Additional tasks include the preparation and characterization of radiochemical standards, environmental monitoring, and process development support.

Wet-chemical and radiochemical analyses are carried on around-the-clock to support waste management and characterization activities. Analyses of environmental, effluent, process chemical, high level tank samples, and nonroutine samples are conducted. Environmental and effluent samples include those taken from liquid effluents, ground and surface waters, soil, animals, vegetation, and air filters. Nonroutine samples include activities to assist in personnel decontamination, and special samples as may be required by process engineering.

The current mission of the 222-S Laboratory is to provide quality analytical and process chemistry services in support of Hanford Site processing plants with emphasis on waste management, chemical processing, environmental monitoring programs, and high level waste characterization. 


\subsection{History/Scheduled Life}

The 222-S Laboratory Complex facilities were built in 1950, 1951, and 1952 to provide analytical and plant support for the Hanford Reduction Oxidation (REDOX) Plant. Through the years, the missions of the Laboratory have changed to support additional facilities, and modifications have been made in response to new requirements and to increasingly restrictive operating and design criteria.

The scheduled life of the facility is 20 years for project planning. 


\subsection{DOE ORDER 4330.4B REQUIREMENTS}

\subsection{Maintenance Management Program Scope}

The Maintenance Management Program for the 222-S Laboratory encompasses all facilities and auxiliary buildings associated with the 222-S Laboratory Complex. Maintenance activities associated with the 222-S Laboratory are provided for by the 222-S Laboratory maintenance organization. These activities, whether for building upkeep or for repair, calibration and/or rework of equipment, are performed by the 222-S Laboratory maintenance organization. The need for a Master Equipment List (MEL) is presently being evaluated, reference section 4.0.

\subsection{Maintenance Program Requirements}

System and component maintenance requirements are established based on analyses that consider safety classifications, programmatic concerns; risk assessments of the facility, system, and component; requirements derived from technical specifications or Operations Safety Requirements; and operating experiences and maintenance history. They address the following DOE Order 4330.4B requirements:

Requirement: (1) The structures, systems, and components included, using a graded approach and the requirements derived from Technical Safety Requirements.

Discussion: $\quad$ An Interim Safety Basis (ISB) document identifies the authorization basis for 222-S. No safety class equipment was identified.

Requirement: (2) The management systems used to control maintenance activities, including the means for monitoring and measuring the effectiveness of the program and the management of maintenance backlog.

Discussion: $\quad 222-S$ Laboratory maintenance activities are managed and controlled in accordance with WHC-CM-1-8 (HNF-PRO-069), "Work Management and LAP-113-100." WHC-CM-1-8 (HNF-PRO-069) includes means for monitoring and measuring program effectiveness and backlog management through the Job Control System (JCS).

Requirement: (3) The assignment of responsibilities and authority for all levels of the maintenance organization.

Discussion: $\quad$ The Analytical Services Maintenance and Work Control Manager (ASMWC) is responsible for maintaining a trained, qualified staff to support the maintenance needs of 222-S Laboratory. The First Line Maintenance Manager is responsible for directing field work activities. 
Requirement: (4) Mechanisms for feedback of relevant information, such as trend analysis and instrumentation performance/reliability data, to identify necessary program modifications.

Discussion: $\quad$ Addressed in WHC-CM-1-8 (HNF-PRO-069) and monthly performance indicators are published.

Requirement: (5) Provisions for identification, evaluation, and correction of possible component, system design, quality assurance, or other relevant problems.

Discussion: $\quad$ Addressed in WHC-CM-1-8 (HNF-PRO-069) and LO-113-100.

Requirement: (6) Performance indicators and criteria to be utilized to measure equipment, systems, and personnel effectiveness in maintenance activities.

Discussion: $\quad$ Addressed in WHC-CM-1-8 (HNF-PRO-069).

Requirement: (7) Interfaces between maintenance and other organizations (i.e., operations, engineering, quality, training, environment, safety, and health).

Discussion: Defined in WHC-CM-5-4, Section 2, "Organization."

Requirement: (8) A self-assessment program to monitor the effectiveness and efficiency of the maintenance program.

Discussion: $\quad$ A Conduct of Maintenance self-assessment program has been developed for 222-S Laboratory. Assessments are performed quarterly, when deemed appropriate, when major changes to maintenance policy and practice so warrants, or as required by the Order (every two years).

Requirement: (9) Provisions for planning, scheduling, and coordination of maintenance activities.

Discussion: $\quad$ Addressed by WHC-CM-1-8 (HNF-PRO-069), LO-113-100 and the JCS user manual.

\subsection{Graded Approach Strategy}

"Graded Approach" is defined as the depth of detail required for implementation and the magnitude of resources expended for a particular maintenance management element. 


\subsubsection{Overall Strategy and Basis}

A graded approach is used to identify the depth of detail and the level of commitment required to ensure safe and reliable operations, environmental compliance, programmatic mission, and facility preservation. Personnel and public safety, availability of funding, operational safety/reliability, environmental safety/compliance, safeguards and security, programmatic mission, and other facility specific requirements are to be considered when work is prioritized and performed.

\subsubsection{Strategy for Safety Related Items}

222-S has no safety equipment. Various levels of review and approval, work control, procedural detail and requirements, documentation, historical records, and oversight are used to address industrial safety requirements and safety significant systems and equipment. The philosophy for assignment of work priorities and allocation of resources to facility maintenance activities is for correction of discrepancies having a direct impact on facility and personnel safety; other maintenance on items not required for safe operation, or on items considered enhancements or plant betterment.

WHC-CM-3-5 (HNF-PRO-234), "Document Control and Records Management Manual", Section 12.7, "Approval of Environmental, Safety, and Quality Affecting Documents," provides control of appropriate application of maintenance activities. 



\subsection{DOE ORDER 4330.4B CHAPTER II REQUIREMENTS}

\subsection{Evaluation of Compliance Elements}

The Hanford Site has existing programs and administrative guidelines providing for control and implementation of a maintenance program conforming to DOE Order $4330.4 \mathrm{~B}$. Maintenance activities at 222-S Laboratory are performed in accordance with these existing documents and procedures. This Maintenance Management Plan correlates the DOE requirements to the existing program, and where appropriate defines any special maintenance program deviations and/or special program activities analogous to 222-S Laboratory.

\subsection{Maintenance Organization and Administration}

The organization and administration of the maintenance function ensures a high level of performance is achieved through effective implementation and control of maintenance activities. Facility policies reflect striving for excellence in facility maintenance and operation.

\subsubsection{Maintenance Organization Policies}

Objective: $\quad$ To establish and communicate policies, procedures, and standards for the administration, implementation, and control of maintenance activities.

Discussion: $\quad$ Project Hanford and facility-specific policies, procedures, and standards are clearly defined and communicated to WMH personnel through facility orientation, formal and informal training, staff and safety meetings, and required reading programs.

Improvement: WMH is in compliance with the intent of the Order.

\subsubsection{Maintenance Strategy}

Objective: To establish an integrated approach (including all affected organizations) in performance of maintenance activities which uses strategic planning to establish specific goals for the maintenance program.

\section{Discussion: Working Relationships}

The 222-S Laboratory Maintenance Manager supervises maintenance activities and coordinates any interface activities between cross discipline organizations required while performing maintenance at 222-S Laboratory.

Control of maintenance activities is performed by the 222-S Laboratory Work Control Center and the JCS as directed by the operations and maintenance organization. 


\section{Discussion: Long Range Planning}

The 222-S Laboratory Facility Manager is responsible for reviewing long-range planning of major maintenance activities and facility outages, as applicable. A scope for funding and staff resources to meet the needs of the maintenance program is provided for, through budget requests and additional funding as required.

The ASMWC Manager monitors staffing and resource requirements to assure all 222-S Laboratory maintenance tasks can be supported. If any additional training is required to support a task, the Maintenance Manager allocates time for training.

The 222-S ASMWC Manager reviews scheduling requirements of facility activities to ensure adequate staffing is available during periods of anticipated facility needs. Also the manager provides to higher management justification for additional personnel and training.

Present staffing for supervisory, maintenance, and work control personnel is funded for 33.6 full time equivalents (FTE).

Improvement: WMH is in compliance with the intent of the Order.

\subsubsection{Staffing Resources}

Objective: $\quad$ To assemble and maintain a maintenance organization staff selected to prescribed qualification criteria commensurate with the facility mission(s), and maintaining the level of skill for maintenance personnel through training and incentive programs.

Discussion: The 222-S Laboratory Maintenance Manager screens personnel to assure the skill level of the individual craftsman, is commensurate with the risk and complexity of the assigned activities. The maintenance manager provides for assessment of maintenance personnel in accordance with existing site procedures.

A periodic review of maintenance personnel training and performance is performed by the 222-S Laboratory Maintenance Manager and results forwarded to the ASMWC Manager.

The qualifications for maintenance personnel are defined by existing site procedures and ensure personnel are trained and capable of performing work at nuclear facilities.

The 222-S Laboratory Facility Manager reviews staff augmentation requirements to support outages and assigns individuals to review the qualifications of augmentation personnel to assure they adequately provide the necessary and timely support to the facility. 
The ASMWC Manager and the 222-S Laboratory Maintenance Manager review personnel performance and productivity, along with manager recommendations, to ensure qualified maintenance personnel are utilized. Training designed to assist deserving individuals in career progression assignments and activities is made available through existing WMH training programs.

Improvement: An evaluation of personnel resources has been made and staffing needs meet the intent of the Order.

\subsubsection{Goals, and Objectives}

Objective: $\quad$ Establish maintenance goals to monitor maintenance activity progress, detect development of trends (favorable and unfavorable), improve performance, create a safe working environment, and measure the overall maintenance program effectiveness.

Discussion: Corrective maintenance backlogs, open work packages and modification completions are being tracked, but no goals have been established.

Improvement: Establish goals for the maintenance department and establish performance indicators for monitoring performance.

\subsubsection{Accountability}

Objective: $\quad$ To monitor personnel in the performance of their assigned responsibilities and administer recognition or disciplinary actions as appropriate to individual performance.

Discussion: Fluor Daniel Hanford and WMH policies and procedures require annual employee performance appraisals and other evaluations to ensure that personnel are recognized for accomplishments and personnel issues are identified and remedied. Specific job responsibilities and performance expectations are discussed with each individual. Standards of Conduct are defined and communicated to all employees.

Improvement: The existing WMH program satisfies the intent of the DOE Order.

\subsection{Training and Qualification}

A maintenance training and qualification program consistent with DOE Orders $5480.5,5480.6$, 5480.20 , and 5480.18A is established and controlled by WHC-CM-2-15 (HNF-PRO-167-182). 222-S Laboratory maintenance personnel are trained and qualified under the Maintenance Training Program requirements specified in WHC-CM-5-4 and the TMX system. 


\subsubsection{Responsibilities}

Objective: Establish a maintenance training program with a clear definition of requirements and responsibilities for development and implementation. Program development includes input from maintenance managers and supervisors and be closely coordinated with the training organizations.

Discussion: The responsibility for establishing, maintaining, and implementing the maintenance training programs is defined in WHC-CM-2-15, "Training Administration Manual," (HNF-PRO-167-182).

Improvement: Develop a formal training program for skills training specific to job position. Program will be approved by the ASMWC Manager and will be administered by the training organization.

\subsubsection{Maintenance Training Programs}

Objective: Maintenance training programs include courses for all functional aspects of the maintenance activity (e.g., management, planning, engineering, support functions) goals for the maintenance program.

Discussion: All employees receive training in certain fundamentals and job-related courses. However, no formal qualification program exists for maintenance personnel other than facility-specific equipment training. Maintenance managers, supervisors, and technical personnel receive training to assist them in performance of assigned responsibilities.

Improvement: Develop, define, and track a formal training program for managers, supervisors, and technical personnel. The program will be administered by facility training and reviewed by Maintenance management.

\subsubsection{Training Schedules and Support}

Objective: Training lessons must be provided that are compatible with the individual's skills and abilities. Schedules are coordinated between maintenance managers and training organizations to ensure availability of instructors, facilities, and support requirements, as well as availability of trainees.

Discussion: Schedules are established and implemented for training of personnel to identify requirements. Training coordinators maintain current status of employee qualification, schedules to keep employees current, and issue delinquent training reports.

Improvement: The current program meets the intent of the DOE Order. Periodic monitoring will ensure continued compliance. 


\subsubsection{On-the-Job Training}

Objective: $\quad$ Formal OJT training requirements are identified, completed and documented prior to performing the task independently.

Discussion: A limited program for OJT is in existence. Limited funding has restricted the development an OJT program.

Improvement: Develop a formal program for training OJT instructors, including formal documentation of the completed training.

\subsubsection{Qualifications}

Objective: $\quad$ Maintenance management reviews training records and verify that all appropriate testing and/or interviews have been successfully completed before qualification of individuals for a given task.

Discussion: The ASMWC Manager establishes adequate records to verify qualification standards and evaluation methods to guarantee trainee competence.

The ASMWC Manager is directly involved in approving and periodically reviewing the maintenance training program.

Improvement: The program for 222-S Laboratory Maintenance organization complies with existing DOE Order requirements. 222-S Laboratory management continues to periodically monitor this program for conformance.

\subsubsection{Training in Root Cause Analysis}

Objective: An appropriate number of individuals are trained in principles and methods of root cause analysis and various approaches to cause and effect analysis. Individuals are able to support maintenance needs and schedules.

Discussion: Representative WMH managers, supervisors, and others trained in the principles and the methods of root cause analysis are called upon to perform this service. When needed, this team assembles and provides an independent determination of cause and effect. Personnel from other WMH organizations with the requisite training are called upon when necessary. Results are documented and corrective action plans are developed.

Improvement: The program for 222-S Maintenance organization complies with existing DOE Order requirements.

\subsubsection{Training Program Approval, Effectiveness, and Feedback}

Objective: The maintenance manager participates in the review and approval of the maintenance training program and training topic lesson plans. Performance of 
Discussion: The maintenance training program is evaluated in accordance with divisional and WMH-specific procedures. Mechanisms are in place to promote feedback and address concerns, which include comments from trainees at the end of each training session.

Improvement: WMH is in compliance with the intent of the Order.

\subsubsection{Management and Supervisory Training}

Objective: A formalized program is in place to develop and maintain management and supervisory skills. Training provided addresses topics (e.g., personnel interfacing, communications, assessments) necessary for effective management and team building. The training program considers support of career progression for entering the supervisory and management field.

Discussion: The training department provides management and supervisory training including generic areas such as managerial and supervisory skills, accountability, assessment and observation of routine activities, communication skills, teamwork, and company management philosophies. Position-specific Person-In-Charge (PIC) training is provided to first-line supervisors.

Improvement: Present training is sufficient to meet the requirements of the DOE Order.

\subsection{Maintenance Facilities, Equipment, and Tools}

Maintenance facilities, equipment, and tools efficiently support facility maintenance and maintenance training.

\subsubsection{Facilities}

Objective: Shop facilities are designed with a high consideration of industrial safety and convenience to the activities they support. Appropriate environmental control systems are provided, adequate support equipment, storage and lay-down areas are available, and controls are in place for facility use.

\section{Discussion: $\quad$ Shops and Satellite Work Areas}

Shop facilities are adequate to support the industrial safety requirements.

The 222-S Laboratory Maintenance Manager is responsible for assuring shop layout and design is conductive to a safe and efficient working environment.

The amount and type of work being performed in the shop area is normal dayto-day repair and servicing. Any specialized work requiring additional 
environmental controls (e.g., welding, machining, high voltage, radiation control, etc.) is performed at specific designated areas. The 222-S Laboratory Maintenance Manager assesses work and determines where and under what controls the work is performed. Additional satellite work areas and stations will be provided for once a need is determined and funding becomes available.

\section{Discussion: Lay-down and Staging Area}

Lay-down and staging areas are provided for by the facility manager. These areas are segregated according to radiological controls, hazardous materials, application, security requirements, and any other consideration. All areas are clearly marked and administratively controlled.

\section{Discussion: $\quad$ Storage Facilities}

Storage facilities for supplies and parts are provided for within the facility and on the facility grounds.

Specialized storage for radiological control is identified and controlled through HSRCM-1, "Hanford Site Radiological Control Manual", and other existing site requirements and procedures.

Storage of flammable and hazardous materials is performed in accordance with WHC-CM-4-3 (HNF-PRO-096), "Industrial Safety Manual", and other existing site procedures.

\section{Discussion: $\quad$ Temporary Facilities}

No temporary facilities are in use at this time, but may be provided on an asneeded basis.

\section{Discussion Decontamination Facilities}

Decontamination of equipment and tools is performed on an as-needed basis. All contaminated equipment and tools is controlled by HSRCM-1.

Improvement: Present facilities are adequate. ASMWC Manager continually assesses the need for additional work area when work scope changes.

\subsubsection{Tool and Equipment Storage}

Objective: $\quad$ Storage facilities are in appropriate proximity to shops and work areas to support maintenance efficiency. Appropriate environmental controls are in place for personnel and equipment protection.

Discussion: Tool and equipment storage is provided for by the Maintenance organization. Special tool and equipment storage has been identified. The ASMWC Manager addresses any need for additional storage space with the facility 
manager. The facility manager evaluates the need, and if appropriate, provides the maintenance department with additional storage facilities.

Improvement: Presently meets the intent of the DOE Order.

\subsubsection{Office Equipment}

Objective: $\quad$ Office equipment necessary to support an efficient maintenance program is available (e.g., furniture, computers, communications, reproduction).

Discussion: Adequate communication, calculation, reproduction, and other office equipment is provided for by $222-\mathrm{S}$ Laboratory facility management.

The computer department, (PHMC), ensures adequate terminal and interface hardware are provided at 222-S Laboratory. LAN systems and file server requirements are provided for.

Improvement: Presently meets the intent of the DOE Order.

\subsection{Types of Maintenance}

A proper balance of corrective and preventive maintenance should be employed to provide a high degree of confidence facility equipment degradation is identified and corrected, that equipment life is optimized, and the maintenance program is cost effective.

\subsubsection{Master Equipment List}

Objective: Develop (and maintain) a MEL for use in identifying equipment safety classifications and maintenance program scope, and development of the equipment history file.

Discussion: There presently is not an updated MEL for 222-S Laboratory. Funding for an updated MEL has been requested for in the FY-98 budget.

Improvement: Upon budget approval, generate an MEL.

\subsubsection{Types of Maintenance}

Objective: Develop a maintenance program that establishes an appropriate, and cost effective, balance of preventive, predictive, and corrective maintenance to minimize equipment downtime and provide a high degree of confidence that facility equipment degradation is identified and corrected.

\section{Discussion: $\quad$ Corrective Maintenance}

222-S Laboratory maintenance personnel perform corrective maintenance activities in accordance with existing site procedures. Corrective maintenance is documented and controlled in accordance with WHC-CM-1-8 (HNF-PRO. 
069), "Work Management." Feedback to the Cog Engineer is through the JCS program and maintenance supervision.

\section{Discussion: Preventive Maintenance}

The 222-S ASMWC Manager implements an effective preventive maintenance program including systems and equipment affecting safe and reliable facility operation. As part of the maintenance surveillance program, the ASMWC Manager ensures functional tests of installed equipment and/or systems (such as standby equipment or non-operating equipment scheduled for rotation) are conducted and documented. This is performed as part of post-maintenance testing activities and documented on the JCS.

Preventive maintenance is performed at predetermined and scheduled intervals, as prescribed by the Cog Engineer, and seeks to maximize equipment availability. Preventive maintenance documentation provides a record of activities performed, data collected, and, where appropriate, the "as-found" and "as-left" condition of the equipment, and supplies this information to the JCS and Component Based Recall System.

The maintenance department acquires trending data as part of the maintenance surveillance program for long-term performance evaluations, such as bearing temperatures, pump speed, and vibration data.

A program for calibration and servicing of specialized laboratory equipment is integrated into the PM program. The Cog Engineer evaluates the preventive maintenance program for effectiveness and changes it where necessary. The Cog Engineer is responsible for determining the type of PM and the frequency for performance.

\section{Discussion: Predictive Maintenance}

Through the JCS status and equipment history records, the need for preventive maintenance is identified in advance of equipment failure. The 222-S Laboratory Engineering Manager has a "limited" program of data gathering which provides information for analysis, trending, and actions needed in advance of equipment failure.

The predictive maintenance program uses the equipment history program and provides information to the preventive maintenance program. When root cause analysis is performed, the resultant information is fed back into the predictive maintenance program through existing administrative guidelines and entered into the historical record.

The Cog Engineer analyzes and reviews predictive maintenance data to ensure the data collected may be successfully used to predict and address incipient failures. 
The need for expanding the predictive maintenance program has been evaluated and been determined not to be cost effective. Engineering will keep abreast of predictive maintenance techniques and analyze the need for expanding the program.

Improvement: The existing maintenance program at 222-S Laboratory is adequate to maintain a maintenance program conforming to DOE Orders and guidelines. The maintenance program will continually be monitored for needed improvements.

\subsubsection{Maintenance Action and Frequency Selection}

Objective: $\quad$ Maintenance frequencies are established to satisfy code and specification requirements, and to ensure optimum equipment operating life and performance.

Discussion: The Cog Engineer reviews 222-S Laboratory equipment history periodically to ensure PMs and their frequencies are used to improve equipment performance.

The 222-S ASMWC Manager evaluates maintenance actions and their frequencies to ensure code and regulatory requirements are being met.

The preventive maintenance program is modified as necessary from review and analysis of historical data by the $\operatorname{Cog}$ Engineer. This ensures the maintenance program is cost effective and required maintenance intervals are adequate. Any change to the maintenance program is documented.

Improvement: No improvements are needed.

\subsubsection{Scheduling}

Objective:

Preventive maintenance activities are scheduled according to assigned frequencies and in conjunction with corrective maintenance of the same equipment or with other activities related to equipment.

Discussion: The ASMWC Manager reviews the JCS periodically to determine if a proper balance of preventive to corrective maintenance activities are being performed. This review determines when it may be advantageous to perform maintenance activities on related equipment, loop components, or on equipment in close proximity. This ensures equipment maintenance is optimized, productivity is increased, and facility downtime is minimized.

Improvement: The JCS database is continually reviewed for related corrective maintenance prior to scheduling preventive maintenance. No improvement is needed.

\subsection{Maintenance Procedures}

Maintenance procedures and other work-related documents (e.g., drawings and instructions) are prepared and used to provide appropriate work direction and to ensure that maintenance is 
performed safely and efficiently. A balance of written guidance, craftsman's skills, and worksite supervision (graded approach) is required to achieve the quality workmanship essential to safe and reliable facility operation.

\subsubsection{Procedure Development and Writing}

Objective: $\quad$ Maintenance procedures are prepared by well qualified personnel, knowledgeable about maintenance standards and administrative procedures, and familiar with the system and equipment involved.

Discussion: The ASMWC Manager establishes guidelines for when a procedure needs to be developed to support testing. Procedures are developed by facility engineering or by other WMH procedure development resources, for, and used, in all work that could result in degraded facility reliability, personnel or equipment hazards, or when the complexity of the work deems a procedure appropriate. Procedures also define preventive maintenance activities.

The 222-S ASMWC Manager ensures all procedures are developed and formatted in accordance with site standards, and departmental desk instructions.

Improvement: The existing program meets the intent of the DOE Order.

\subsubsection{Procedure Verification}

Objective: $\quad$ Procedures are reviewed for format and technical accuracy. Format use incorporates human factors principles and other administrative policies. Reviews are conducted by other than the procedure writer.

Discussion: The 222-S Laboratory Engineering Manager ensures all procedures are verified in accordance with WHC-CM-3-5 (HNF-PRO-233), "Document Control and Records Management Manual," Section 12.7, "Approval of Environmental, Safety, and Quality Affecting Documents."

Improvement: At present, the existing procedure verification program is adequate to meet the requirements of the DOE Order.

\subsubsection{Procedure Validation}

Objective: $\quad$ Procedures are reviewed for usability and correctness to ensure sufficient and understandable instructions are provided and are compatible to the equipment and task specified.

Discussion: The 222-S Laboratory Maintenance Manager and crafts ensure all procedures are field validated in accordance with WHC-CM-1-8 (HNF-PRO-069).

Improvement: The present program satisfies the requirements of the DOE Order. 


\subsubsection{Procedure Approval}

Objective: $\quad$ Procedures are reviewed to applicable specifications and administrative procedures and approved by appropriate levels of management.

Discussion: The 222-S Laboratory Maintenance Manager and Facility Engineering ensure all procedures are approved in accordance with WHC-CM-3-5 (HNF-PRO233), Section 12.7 .

Improvement: All procedure approvals are made in accordance with WHC-CM-3-5 (HNFPRO-233), Section 12.7. There are no improvements identified or required at this time.

\subsubsection{Procedure Use}

Objective: $\quad$ Procedure control is established ensuring availability and currency of the procedures to be used. Procedure compliance requirements are clearly stated, communicated, and understood by users.

Discussion: Work Control ensures procedures used in the field are the most current and correct revision for use. Document Control issues and controls maintenance procedures per existing plant procedures.

The 222-S Laboratory Maintenance Manager ensures a graded approach is used to provide the need for work procedures used by the maintenance organization and in accordance with the requirements of WHC-CM-1-8 (HNFPRO-069).

The Laboratory Engineering Manager ensures all procedures are changed and revised in accordance with WHC-CM-5-4. Procedure compliance is reviewed by all craft annually.

Improvement: The present program satisfies the requirements of the DOE Order.

\subsection{Planning, Scheduling, and Coordination of Maintenance}

An effective system for planning, scheduling, and coordinating maintenance activities are implemented in order to ensure that maintenance is accomplished in a timely manner, improve maintenance efficiency, reduce radiation exposure, and increase equipment availability.

\subsubsection{Planning for Maintenance Activities}

Objective: $\quad$ Establish a planning program that provides work instructions, identifies resource requirements, and coordinates support functions. 
Discussion: Planning Group Organization

The planning activities for 222-S Laboratory is performed by the 222-S Work Control and Laboratory Engineering groups, utilizing the JCS in accordance with WHC-CM-1-8 (HNF-PRO-069), "Work Management."

Discussion: $\quad$ Planning Group Responsibilities

The 222-S Work Control and Laboratory Engineering groups are responsible for all planning activities at 222-S Laboratory. The planning organization performs work activities in accordance with existing site procedures.

Improvement: Compliance with the DOE Order is met.

\subsubsection{Scheduling Maintenance Activities}

Objective: All maintenance activities are performed using a clearly defined schedule, supported by all affected organizations, tracked to maintain status, and performed according to priorities established by operations.

Discussion: Control of Work Backlog

The 222-S Building Operations Manager specifies priorities to assure work is performed on schedule. Work backlog is tracked and controlled within the JCS in accordance with the requirements of WHC-CM-1-8 (HNF-PRO-069), "Work Management." The 222-S Building Operations Manager is responsible for reviewing the backlog for work status and problem areas. The scheduling of work packages and work activities is performed through the JCS, the Work Control Group, and the 222-S Building Operations Manager.

222-S Laboratory JCS activities are performed in accordance with applicable sections of LAP-113-100, "Job Control".

\section{Discussion: Work Priority}

The 222-S Building Operations Manager assigns work priorities on the basis of safety and operational requirements, using the graded approach. This is controlled by the requirements of WHC-CM-1-8 (HNF-PRO-069) and LAP113-100.

The facility manager may increase specific task work priority if deemed necessary and appropriate.

The Weekly Priority Meeting, Plan-of-the-Week, and Plan-of-the-Day are used for integrating work priorities with the long range schedule.

Improvement: The present program meets the intent of the DOE Order. 


\subsubsection{Coordination of Maintenance Activities}

Objective: $\quad$ Coordinate maintenance activities to ensure that work can be effectively accomplished.

Discussion: $\quad$ Routine planning meetings are held to ensure coordination of activities. The 222-S Building Operations Manager and Work Control groups provide the necessary supervision to assure all maintenance activities are performed in cooperation and coordination with other departments.

Improvement: Compliance with the DOE Order is met.

\subsubsection{Outage Planning, Scheduling, and Coordination}

Objective: $\quad$ Establish program for identifying all maintenance activities to be performed during a defined facility or equipment outage and develop schedule for planning and performance of those activities.

Discussion: Outage planning is normally not applicable to the 222-S Laboratory as there are no systems or major pieces of equipment requiring advance scheduling and outage planning.

Improvement: As major outages are identified, a program will be established to ensure required maintenance activities are coordinated, statused, and performed. There is no improvement required at this time.

\subsection{Control of Maintenance Activities}

Management directed and delegated involvement in control of maintenance activities ensure maintenance practices are effective in maintaining safe, efficient, and reliable facility operation.

\subsubsection{Work Control Procedure}

Objective: $\quad$ Work Control is accomplished in accordance with a formal program which defines the requirements and controls for performing work. The program is used to identify all facility deficiencies, modifications, preventive maintenance and surveillance testing, avoid redundant identification of deficiencies, and post-maintenance activities.

Discussion: WHC-CM-1-8 (HNF-PRO-069) and LAP-113-100 are the administrative procedure describing Work Control requirements at 222-S.

Improvement: The WMH administrative policies and procedures applying to Work Control comply with the DOE Order. 


\subsubsection{Work Request}

Objective: All maintenance activities performed are controlled by the facility work control program. Work request documents clearly define work to be performed, equipment on which work is to be performed, pre- (and post-) requisites, and documentation requirements. Work requests are reviewed by affected organizations before release for work and upon completion of work.

Discussion: The work request process is controlled through the application of the JCS program in accordance with WHC-CM-1-8 (HNF-PRO-069) and LAP-113100.

Work requests are reviewed in accordance with the requirements of and WHC-CM-3-5 (HNF-PRO-233), Section 12.7.

Improvement: The present work request system complies with the DOE Order.

\subsubsection{Supervision of Maintenance Activities}

Objective: Maintenance managers routinely monitor work in progress to ensure maintenance activities are conducted in accordance with facility procedures and work package instructions. Problems observed are analyzed and feedback is provided to prevent recurrence.

Discussion: $\quad 222-S$ Laboratory Maintenance Managers routinely monitor work in progress to help ensure maintenance activities are conducted in accordance with DOE and Site policies and procedures, per WMH job descriptions and standard industry practice.

Improvement: The present supervisory and management overview of work activities complies with DOE Order.

\subsubsection{Review of Completed Work Requests}

Objective: $\quad$ Completed work packages are reviewed to verify all work items, including post-maintenance testing and inspections, have been completed in an acceptable manner before returning system or equipment to service.

Discussion: When maintenance work is performed, the 222-S Building Operations Manager compares the work performed to the post-maintenance testing or inspection result to determine all work is acceptable prior to returning the equipment or system to normal service.

The Cog Engineer, Operations, or 222-S Laboratory Maintenance Manager may request post-maintenance testing in addition to post-maintenance tests already specified on the work package, if the scope of the work performed deems additional testing. 
The Cog Engineer recommends closure of the work package after review.

Improvement: The present program and policies affecting completed work packages complies with the intent of the DOE Order.

\subsubsection{Temporary Repairs}

Objective: Temporary repairs are accomplished and controlled to the same level as permanent repairs.

Discussion: Temporary changes and modifications are performed in accordance with the requirements of WHC-CM-6-1 (HNF-PRO-446), "Standard Engineering Practices," and JCS. Temporary repairs or changes are converted to permanent repairs or official design modifications in a timely manner, as required by applicable site procedures.

Improvement: The present program for changes complies with the DOE Order.

\subsubsection{Control of Nonfacility Contractor and Subcontractor Personnel}

Objective: Nonfacility contract and subcontract personnel who perform maintenance or modification work on 222-S Laboratory systems are qualified for the work performed and trained in accordance with access requirements.

Discussion: Site procedures provide for access control and general employee training of contractor.and subcontractor personnel. 222-S Building Operations assures any additional training required for contractor or subcontractor personnel is performed and documented in accordance with site procedure. Qualification of contractor personnel is certified by the contractor, and verified and documented by the Cog Engineer before commencement of work activities.

Improvement: The existing policy is adequate to meet the intent of the DOE Order.

\subsection{Post-Maintenance Testing}

Post-Maintenance testing is performed to verify components can fulfill their design function when returned to service after maintenance.

\subsubsection{Post-Maintenance Test Requirements}

Objective: The work completion and retest process at WMH addresses control and documentation of retest requirements. Work requests provide specific instructions for test and acceptance criteria when maintenance work is performed.

Discussion: Post-maintenance testing is conducted in accordance with WHC-CM-1-8 (HNF-PRO-069) when maintenance work has been performed and when specified by the $\operatorname{Cog}$ Engineer or Operations. 
Improvement: The post-maintenance test program meets the intent of the DOE Order.

\subsubsection{Post-Maintenance Test Program Scope}

Objective: All maintenance activities are reviewed for applicability of post-maintenance testing and appropriate testing instructions (and acceptance criteria) are provided.

Discussion: $\quad$ Post-maintenance testing at 222-S Laboratory is performed when the work instructions specify the requirement.

Improvement: The existing program meets the intent of the Order.

\subsubsection{Post-Maintenance Test Control}

Objective: The Work Control program addresses control of post-maintenance testing that covers all conditions of single or multiple organization involvement and testing that is deferred until a later date.

Discussion: During work package closeout and review, retesting may be specified by operations before work package completion. If the retest cannot be performed immediately and needs to be tracked, 222-S Work Control statuses and tracks the retest requirement per WHC-CM-1-8 (HNF-PRO-069).

Improvement: The post-maintenance test control process meets the intent of the Order.

\subsubsection{Post-Maintenance Test Performance Documentation, and Acceptance}

Objective: $\quad$ Post-maintenance testing is performed in accordance with approved work package instructions (or preventive maintenance procedure) and completion is documented.

Discussion: The JCS is used for documenting post-maintenance testing instructions unless specific test requirements are identified. Documentation is performed in accordance with work package closeout and WHC-CM-1-8 (HNF-PRO-069) requirements. Test results are documented and retained as part of the maintenance history.

Upon completion, the work package is reviewed for completion in accordance with WHC-CM-1-8 (HNF-PRO-069) before approval.

Improvement: The existing program meets the intent of the DOE Order.

\subsection{Procurement of Parts, Materials, and Services}

Controls and assessment of procurement activities are used to help ensure that proper parts, materials, and services are purchased to support maintenance activities and to meet the requirements for safe and reliable facility operation. 


\subsubsection{Procurement Policy and Procedures}

Objective: $\quad$ Policies and procedures are in place governing the procurement of parts, materials, equipment, and services. Personnel responsible for procurement activities are conversant to, and comply with, defined requirements.

Discussion: $\quad$ Procedures are in place to provide for the expeditious procurement of parts and material on a high priority basis when needed, as specified in WHC-CM-6-1 (HNF-PRO-447) and WHC-CM-2-1 (HNF-PRO-123), "Procurement Manual and Procedures", prescribes methods to acquire replacement parts not available through the original supplier.

The 222-S Laboratory Work Control Center or Cog Engineer is responsible for procurement of parts and materials associated with 222-S Laboratory maintenance activities. The 222-S Laboratory Maintenance Manager is responsible for procuring parts associated with shop activities and equipment.

Improvement: The existing program meets the intent of the DOE Order.

\subsubsection{Procurement Initiation}

Objective: $\quad$ Procurement activities are conducted in a timely fashion. The procurement program addresses the pre-selection and qualification of procurement sources, spare parts inventory, and cross facility use of inventories.

Discussion: Lessons learned from experience, such as lead times, parts usage, and supplier reliability, are factored into materials management and included in existing site procedures.

Topics such as storage, in-storage preventive maintenance, and shelf-life requirements are addressed in WHC-CM-2-2 (HNF-PRO-129-135).

Warehouse and procurement activities such as inventory, rotation, and other warehouse functions are specifically addressed in existing site procedures.

Improvement: The existing program is adequate to meet the intent of the DOE Order.

\subsubsection{Procurement Control}

Objective: The procurement program provides for documentation and controls applicable to obtaining parts, materials, equipment, and services in accordance with the technical and quality requirements.

Discussion: The Cog Engineer approves any deviation from design specifications for parts or materials.

Warehouse personnel review material and parts activity to determine possible new additions to be included in spare parts or site stores catalog. 
Procurement documents WHC-CM-2-1 (HNF-PRO-123), provide clear and adequate technical and quality assurance requirements consistent with design specifications.

Deficient or nonconforming items are resolved in an effective and timely manner as specified by site procedures.

Quality assurance records are controlled and maintained per WHC-CM-3-5 (HNF-PRO-222) and WHC-CM-4-2 (HNF-PRO-274) to provide documentation for qualified parts and materials and to ensure traceability. The QA department performs audits, inspections or surveillances of suppliers according to $\mathrm{QA}$ requirements.

Improvement: The existing program is adequate to meet the intent of the DOE Order.

\subsubsection{Services}

Objective: A program for selection and procurement of service contracts is in place and a renewal process may be initiated to prevent periods of non-coverage.

Service contracts include provisions for emergency or short notice support.

Discussion: Identification of the need for specialized services from vendors is made by the ASMWC Manager and the Engineering Manager to provide for timely submittal of bidding on and awarding of contracts.

Improvement: The existing procedures meet the intent of the Order.

\subsection{Material Receipt, Inspection, Handling, Storage, Retrieval, and Issuance}

All phases of receiving, inspecting, handling, storing, retrieving, and issuing equipment, parts, and materials for maintenance are covered by effectively implemented policies and procedures consistent with the Quality Assurance Requirements of the facility.

\subsubsection{Receipt and Inspection}

Objective: $\quad$ Receipt inspections of materials and equipment are performed before acceptance for use or storage verifying items delivered conform to all procurement document requirements and are in good condition.

Discussion: WHC-CM-2-1 (HNF-PRO-123) and WHC-CM-2-2 (HNF-PRO-135) are prepared to specifically describe the responsibilities and techniques for receiving, inspecting, handling, storing, retrieving, and issuing equipment, parts, and materials.

Material is inspected per the requirements of WHC-CM-2-2 (HNF-PRO-135) to ensure conformance to purchasing requirements prior to release for use and storage. 
Site procedures control documentation for received material and assures that these documents are accounted for and retrievable.

WHC-CM-4-2 (HNF-PRO-299/300) specifies nonconforming items are identified with tags or labels and controlled to prevent unauthorized use.

Improvement: Site procurement and receipt inspection is presently governed by existing procedures and programs and requires no improvement at this time.

\subsubsection{Handling}

Objective: Procedures are provided for items requiring special handling. Procedures include all information necessary to prevent damage.

Discussion: WMH site procedures/instructions are available for items requiring special handling.

Effective material procurement status is provided, including accurate stock records and tracking of purchase orders.

Improvement: The existing process for special handling meets the intent of the Order.

\subsubsection{Storage Material and Equipment}

Objective: $\quad$ Materials and equipment are stored in a manner to provide maximum protection, but remain readily available for issue. Safety-related equipment is segregated from nonsafety items to prevent improper usage.

Discussion: Materials are stored, protected, and identified in accordance with WHC-CM-2-2 (HNF-PRO-129/134/135) in a manner that provides ready availability for its intended use.

A shelf-life control program WHC-CM-2-2 (HNF-PRO-129/134/135) is provided for store items that are important to safe and reliable facility operation.

Safety-related and nonsafety-related materials and equipment are segregated from each other to prevent inadvertent use of the wrong category of item.

Periodic inspections of staging areas, stores, and warehouses are performed by the 222-S Maintenance Manager and the ASMWC Manager.

The quality of stored equipment, parts, and materials is maintained in accordance with vendor information by appropriate means, such as environmental and shelf-life controls and preventive maintenance activities, if necessary.

Improvement: Warehouse storage complies with the DOE Order. 


\subsubsection{Retrieval and Issuance}

Objective: $\quad$ Parts, materials, and equipment removed from storage are handled to the same requirements applied at time of receipt. A stores inventory system is in place to identify available materials and equipment and is available to using organizations, such as planning and engineering.

Discussion: Parts and materials issued for installation are properly controlled per existing site procedures. Unused parts and materials are promptly returned to a controlled storage area. Completed work requests/orders document material traceability.

Improvement: The program complies with the DOE Order.

\subsection{Control and Calibration of Measuring and Test Equipment}

The program for control and calibration of measuring and test equipment (M\&TE) are consistent with the Quality Assurance requirements of DOE 5700.6C and ensure the accurate performance of facility instrumentation and equipment for testing, calibration, and repairs.

\subsubsection{Identification}

Objective: $\quad$ Establish a program for the assignment of a unique identification number for each item of M\&TE which is permanently marked or attached to the equipment and a master M\&TE equipment list for use in control of the equipment.

Discussion: All M\&TE devices used at WMH have unique identification numbers accurately identifying the specific devices and provide positive traceability. A master list identifying all M\&TE is developed and kept current by the Standards Laboratory.

Improvement: The existing program complies with the intent of the Order.

\subsubsection{Calibration}

Objective: $\quad$ Calibration of M\&TE at WMH is accomplished by qualified personnel using approved procedures and standards having full traceability to the National Institute of Standards and Technology or other nationally recognized standards. Standards utilized are maintained at designated controlled storage locations.

\section{Discussion: Calibration Standards}

The M\&TE calibration program is based on standards traceable to a national standard or that are recognized standards unto themselves. All traceability, administrative controls and guidelines, are already in place as part of the PHMC site M\&TE program. Records are maintained at the Standards Lab. 


\section{Discussion: Calibration Procedures}

Procedures WHC-CM-4-2 (HNF-PRO-288/290) are used to calibrate M\&TE, control the performance of calibrations, provide repeatable calibrations, and provide acceptance criteria.

M\&TE documentation includes records for accountability and traceability of use. A recall system is developed for recalibrations of M\&TE. This system is controlled by the M\&TE Standards Lab. All M\&TE calibrations are performed through the administrative controls and requirements of the M\&TE Standards Lab.

\section{Discussion: Calibration Frequency}

A calibration frequency to maintain M\&TE accuracy and availability is established through the PHMC M\&TE administrative program and WHC-CM-4-2 (HNF-PRO-288/290), "Quality Assurance Manual," Section 12, "Control of Measuring and Test Equipment," requirements.

\section{Discussion: Functional Checks}

PHMC site procedures recommend M\&TE be functionally checked before use and this is performed on an as-needed basis by 222-S Laboratory maintenance personnel.

Improvement: The present program is in compliance with the DOE Order.

\subsubsection{Control}

Objective: Control of M\&TE is established to ensure equipment used to verify (calibrate) facility instrumentation operates properly.

\section{Discussion: $\quad$ Storage}

Control of M\&TE is established by WHC-CM-4-2 (HNF-PRO-288/290), to ensure equipment used to verify (calibrate) facility instrumentation operates properly.

A room at 222-S Laboratory is provided to control storage and issuance of M\&TE. The 222-S Laboratory Maintenance Manager identifies storage areas.

Any M\&TE with suspected or actual deficiencies is segregated and marked to prohibit its use as required by existing site procedure. 
Discussion: Uncalibrated M\&TE

New M\&TE devices are calibrated prior to use. Uncalibrated M\&TE for taking data at WMH facilities are clearly identified and their use is strictly controlled by facility and site procedures. 222-S Laboratory follows this program.

\section{Discussion: M\&TE with Limited Use}

M\&TE devices not fully calibrated or usable are clearly marked to indicate their limitations and are not issued for quality work at WMH. This program is also adhered.

\section{Discussion: Issue and Recall}

The Standards Lab has administrative procedures in place for notification of calibration due dates and M\&TE recall. M\&TE usage is tracked by the maintenance department using the work request, the calibration data sheet, and/or the checkout sheets.

\section{Discussion: Contaminated M\&TE}

Contaminated M\&TE is controlled per existing safety and radiological guidelines at WMH and is adhered to at 222-S Laboratory. Contaminated M\&TE is strictly controlled to minimize the spread of contamination.

Improvement: There are no improvements identified or required at this time.

\subsubsection{Evaluation}

Objective: Usage of M\&TE is controlled and evaluated to ensure proper utilization, impact/consequence of out-of-tolerance equipment use, and equipment reliability.

\section{Discussion: Out-of-Calibration and Defective M\&TE}

M\&TE devices found out of calibration or defective receive timely evaluations to determine the validity of all measurements/tests for which they were used. This is accomplished through the review of history files controlled through the JCS/PMS program.

\section{Discussion: Performance Trending}

Results of M\&TE calibrations are trended by the Standards Lab and the Cog Engineer, corrective actions are determined for any M\&TE reliability problems.

Improvement: There are no improvements required at this time. 


\subsection{Maintenance Tools and Equipment Control}

Methods are established to provide for storage, issuance, and maintenance of an adequate and readily available supply of tools and equipment and also for the development of special tools and equipment needed in the maintenance program.

\subsubsection{Storage and Issuance}

Objective: To ensure that an adequate supply of hand tools, common power tools, and equipment is readily available, properly stored, and controlled.

Discussion: Overall responsibility for assuring 222-S Laboratory has proper tools to perform maintenance activities and that they are stored properly, is with the Maintenance Manager. Specialized requirements are identified and steps taken to procure the equipment if required. This specialized equipment is stored in the M\&TE storage area.

WHC-CM-4-3 (HNF-PRO-085) controls the disposition of worn and defective tools. The 222-S Laboratory maintenance organization works to these controls and guidelines.

Improvement: Existing site policies provide for an effective program to procure and maintain specialized tools and equipment. Meets the intent of the Order.

\subsubsection{Tool and Equipment Maintenance}

Objective: $\quad$ Tools and support equipment are included in the preventive maintenance program to maintain a safe use condition and to provide necessary care to maintain its service life.

Discussion: Maintenance tools and other support equipment used at 222-S Laboratory, if cost effective, are included in the preventive maintenance program by the 222-S Laboratory maintenance organization.

Existing WMH programs and policies provide for the care and servicing of tools and support equipment.

Improvement: There is no program improvement required at this time.

\subsubsection{Use of Special Tools and Equipment}

Objective: $\quad$ Special tools and equipment are available and are clearly marked for their intended use. Work packages include necessary instructions for the proper use of special tools and equipment.

Discussion: Special tools, test rigs, special equipment, lifting and rigging equipment, and mockups required for maintenance activities at 222-5 Laboratory, are 
identified for their intended use by the 222-S Laboratory maintenance organization.

Specific Instructions are provided to control the use of lifting and rigging equipment in DOE-RL-92-36, "Hanford Site Hoisting and Rigging Manual." The 222-S Laboratory maintenance organization abides by these guidelines.

Improvement: WMH special tools and equipment program meets the requirement of the Order.

\subsection{Facility Condition Inspection}

Management conducts periodic inspections of equipment and facilities to assure excellent facility condition, housekeeping, and safe and reliable operation.

\subsubsection{Standards}

Objective: Management conducts periodic inspections of equipment and facilities to assure excellent facility condition and housekeeping. The condition of a facility is dependent on many factors, including design, fabrication, modifications, ongoing maintenance, the facility work control programs, and day-to-day operation. After initial facility construction, ongoing maintenance and the control of modifications are prime contributors to keeping systems and equipment in optimum condition to support safe and reliable operation.

Discussion: $\quad 222-S$ management team performs inspections of all 222-S Laboratory facilities on a regular basis to ensure standards are maintained.

Managers set high facility condition and housekeeping standards and communicate them to all personnel to provide a clear understanding of these standards.

Housekeeping inspection program for $222-\mathrm{S}$ is specified in WHC-CM-5-4.

Improvement: At the present time, existing site procedures and programs comply with the intent of the DOE Order.

\subsubsection{Training}

Objective: Personnel involved in facility inspections receive instructions to establish knowledge of standards and related facility policies. Methods for determining condition status are provided for consistency of inspections and condition reporting.

Discussion: The 222-S Laboratory Manager is responsible for communicating inspection criteria and techniques required to perform 222-S Laboratory condition inspections as referenced in WHC-CM-5-4. Safety inspection check sheets are available to the inspectors. 
Improvement: At the present time the program meets the intent of the DOE Order.

\subsubsection{Procedures}

Objective: Procedures are provided defining the facility inspection program, methods of implementation, standards of condition, and means for correction of deficiencies found. Deficiencies found are evaluated for changes to the facility maintenance program.

Discussion: Existing WMH procedures and WHC-CM-5-4 describe the facility inspection program and good housekeeping requirements. Reporting and tracking deficiencies is provided.

Improvement: The present system of inspections and identification of deficiencies is well defined and in compliance with the DOE Order.

\subsubsection{Scope of Inspections}

Objective: Inspections include detailed walkdowns of assigned areas that include remote and limited-access areas as well as the more obvious and available areas.

Key individuals are included in the inspection teams with free discussion of techniques and concerns encouraged. Sufficient time is allowed to search for deficiencies rather than a quick walkthrough. Obvious deficiencies are investigated to the degree necessary to positively identify the source of the problem.

Discussion: Inspections are performed following established WMH procedures and include walkdowns of 222-S Laboratory maintenance areas. The inspections are confined to the main 222-S Laboratory building and 222-S out buildings where activities are performed. The 222-S Laboratory Manager is responsible for ensuring all 222-S Laboratory areas and buildings are inspected on a regular basis. Inspection routes and schedules are created to ensure all areas requiring inspection are being inspected on a routine basis.

Improvement: The inspection program meets the intent of the DOE Order.

\subsubsection{Inspection Program Elements}

Objective: Inspection assignments are scoped to ensure adequate time for thorough inspection and scheduled to minimize impact to ongoing operations of the facility.

Discussion: The 222-S Laboratory Manager establishes a scheduled walkdown inspection on a regular basis. This schedule identifies personnel assigned inspection responsibility, the area to be inspected, and any additional inspection requirements (reference WHC-CM-5-4).

Improvement: The inspection program meets the intent of the Order. 


\subsubsection{Reporting Deficiencies}

Objective: Deficiencies noted during inspection are entered into the work control program for corrective action. Significant and/or safety related deficiencies are assigned the appropriate priority and reported to the responsible facility manager. Housekeeping deficiencies are reported to the occupying organization for attention.

Discussion: Inspection results are documented and a report presented to the Facility Manager. Items identified as deficient are tagged or identified to permit easy identification if it is defective or suspect.

Significant facility condition and safety deficiencies observed are immediately reported to the shift supervisor for appropriate near-term attention.

Maintenance deficiencies are entered into the JCS system using the work identification document.

Improvement: The existing site program is adequate and meets the intent of the DOE Order.

\subsubsection{Deficiency Follow-up}

Objective: $\quad$ Reported deficiencies are monitored for timely completion of corrective actions. Recurring, generic, or long term problems are analyzed for identification of root cause. Recommendations are provided for changes to the preventive maintenance program. Periodic evaluation of inspection reports and facility conditions are made to determine program effectiveness.

Discussion: Identified deficiencies requiring immediate corrective action have a work order initiated, the deficient equipment is identified, and the JCS tracks the item for corrective action. The 222-S Laboratory Manager is responsible for informing inspection personnel and concerned parties of deficiency resolutions in a timely manner, and tracking reported deficiencies to completion.

Improvement: The present program is adequate and meets the requirements of the DOE Order.

\subsection{Management Involvement}

To ensure the safety of DOE facility operations, DOE and contractor corporate and facility managers are sufficiently involved with facility operations to be technically informed and personally familiar with conditions at the operating facility. 


\subsubsection{Management Involvement}

Objective: Management conducts periodic inspections of equipment and facilities to assure excellent facility condition and housekeeping. The condition of a facility is dependent on many factors, including design, fabrication, modifications, ongoing maintenance, the facility work control programs, and day-to-day operation.

After initial facility construction, ongoing maintenance and the control of modifications are prime contributors to keeping systems and equipment in optimum condition to support safe and reliable operation.

The involvement of facility managers and supervisors in periodic facility walkdowns and inspections clearly displays management standards to all personnel and can significantly improve the condition of the facility. A program for identification and dispositioning of facility condition deficiencies and housekeeping discrepancies is an important step in maintaining facilities and equipment in a condition of maximum safety, reliability, and availability.

Discussion: The 222-S Laboratory managers personally walk through the 222-S Laboratory on a routine basis. This walkthrough is performed to improve face-to-face communication and feedback at all levels of maintenance and to set standards for facility condition and housekeeping.

The 222-S Laboratory Managers ensure appropriate personnel receive inspection techniques training and assigns inspection areas to ensure the entire facility is periodically inspected, including areas with difficult access (e.g., high radiation areas and locked areas).

Identified deficiencies are reported and corrected in a timely manner so personnel can see the positive results of the inspection program.

Improvement: The present program meets the requirements of the DOE Order.

\subsubsection{Performance Indicators, Goals, and Objective Results}

Objective: Performance indicators are established, maintained, and trended to provide visibility of organizational goals and objectives. Information is used to observe developing trends and formation of corrective action and recovery plans.

Discussion: The ASMWC Manager uses performance indicators to establish trends and provide feedback to the maintenance organization. These trends provide the maintenance organization with a means for assessing maintenance tasking and performance and allow for corrective action recommendations.

Improvement: Formal goals and objectives for the maintenance organization need to be developed and performance indicators established to track goals. 


\subsubsection{Feedback}

Objective: $\quad$ Feedback systems are in place to provide means for continuous communications between all groups, worker disciplines, and management levels. Methods are in place to apply lessons learned from experiences of others, and in-house, to ensure long-term success. All levels of management are available to discuss problem areas and suggested improvements.

Discussion: $\quad$ A feedback system such as the open door policy has been established to promote communications and participation for improvement at all levels of the maintenance program. Lessons learned, daily team meetings, and required reading provide a method to improve performance and promote safety.

Improvement: At present the existing programs meet the requirements of the Order.

\subsubsection{Program Reviews}

Objective: $\quad$ Managers periodically review and assess all elements of the maintenance program to identify areas requiring improvement or corrective action. Input of managers and supervisors, and other supporting organizations, is utilized in program review. Areas requiring improvement are assigned for corrective action and followup.

Discussion: $\quad$ At 222-S Laboratory the ASMWC Manager follows a program of reviews and self-assessments. The feedback from self-assessments and reviews determines changes to the maintenance policy of the maintenance organization. Quarterly assessments of selected chapters of the DOE Order are made.

\section{Discussion: $\quad$ Assessment of Facility Condition and Worker Practices During Maintenance}

Periodic assessments of specific programs, such as the PM program, are performed per site procedure. 222-S Laboratory specific program evaluation is provided for by the ASMWC Manager as the need for such an evaluation becomes apparent through audits and assessments.

The ASMWC Manager periodically reviews personnel performance and work practices. This review is directed at improving worker performance. Appraisals are performed in accordance with site procedures.

Equipment and component maintenance history is trended through the application of the JCS program. The Cog Engineer reviews this history for maintenance trends or problems.

\section{Discussion: Assessment of Maintenance Training}




\section{Discussion: Assessment of Procurement Activities}

Periodic assessment of the procurement process are performed by the PHMC and ASMWC management for timeliness and responsiveness.

Discussion: Assessment of Measuring and Test Equipment

ASMWC Manager assess the M\&TE program for availability of M\&TE and safe and reliable operation of equipment in support of 222-S Laboratory.

Improvement: The existing assessment program is adequate and meets the requirements of the DOE Order.

\subsection{Maintenance History}

A maintenance history and trending program is maintained to document data, provide historical information for maintenance planning, and support maintenance and performance trending of facility systems and components.

\subsubsection{Program Development}

Objective: $\quad$ A program is in place identifying critical (from the SAR) systems and equipment requiring documentation and retention of historical data.

\section{Discussion: Equipment Identification}

Each piece of laboratory equipment is given a unique identifier. The present program follows the guidelines; however, the Master Equipment List (MEL) is incomplete.

\section{Discussion: Data Identification}

Completed work packages under the JCS program include all relevant maintenance data for a given critical piece of equipment. Specific data requirements for a given piece of 222-S Laboratory equipment not previously identified are provided by the Cog Engineer.

Improvement: Complete a Master Equipment List (MEL) to ensure maintenance history can be tracked.

\subsubsection{Data Collection}

Objective: Information for systems and equipment identified for record history retention is forwarded to a specified organization for control, reviewed for 
completeness and correctness, and entered into the equipment history program.

Discussion: Data on 222-S Laboratory systems and equipment selected for history retention is controlled through the Job Control System (JCS).

Improvement: At present the existing JCS system is adequate to meet the requirements of DOE Order.

\subsubsection{Program Use}

Objective: Equipment history data is readily available to all organizations and is used in the development of work packages and schedules, and is periodically reviewed for developing trends.

Discussion: The JCS program establishes a maintenance history program. This program is reviewed by (FACILITY) Maintenance Managers, Cog Engineers, or any personnel involved with (FACILITY) maintenance to identify problems or areas where maintenance activities may not be warranted.

Improvement: Periodic review of this program is performed to ensure the program is in compliance with the DOE Order. No improvements are identified or required at this time.

\subsection{Analysis of Maintenance Problems}

Systematic analysis is used to determine and correct root causes of unplanned occurrences related to maintenance.

\subsubsection{Information Collection}

Objective: In preparation of event analysis, all applicable logs, records, recordings, and personnel interview statements are gathered.

Discussion: 222-S Laboratory maintenance activities are mainly confined to environment control systems, analytical instrumentation, and to building utilities.

Maintenance and calibration of special lab equipment is performed and this information is tracked and statused.

Improvement: The present program satisfies the intent of the DOE order.

\subsubsection{Event Analysis}

Objective: In performing an event analysis a detailed sequence of facts and activities is developed and apparent causal factors identified and categorized. 
Discussion: Aspects of root-cause-analysis are presently addressed in site procedures. The activities required by event analysis are performed in accordance with root-cause-analysis procedures and guidelines at 222-S Laboratory.

Improvement: The present program satisfies the intent of the DOE order.

\subsubsection{Cause Determination}

Objective: Actual or probable causes of a problem are evaluated by one or more techniques to establish a final root cause. Appropriate documentation is developed to aid in the analysis, to record analysis performed, and to document corrective action recommendations.

Discussion: 222-S Laboratory personnel performing cause determination are trained in Root-Cause-Analysis and perform activities in accordance with existing site procedures.

Improvement: The present site Root-Cause-Analysis program satisfies the intent of the DOE Order.

\subsubsection{Corrective Action}

Objective: $\quad$ Corrective action plans are developed, initiated, and tracked to completion. Plans address all applicable activities such as repairs, preventive maintenance procedures, and personnel training.

Discussion: . Once cause determination has been performed, corrective action is initiated in accordance with WMH site procedure and tracked by the Occurrence Reporting Processing System, JCS and/or HATS to completion.

Improvement: Existing site procedures and policies are adequate to meet the intent of the DOE Order.

\subsubsection{Corrective Action Follow-up}

Objective: Corrective action followup activities include specific post repair testing and continued monitoring of equipment as positive means to ensure corrective actions taken in fact resolve the problem experience.

Discussion: Equipment corrective action is followed by some type of post-maintenance testing and tracked by the JCS. Procedural or administrative changes are followed by the 222-S Laboratory Maintenance Manager and the training organization.

Improvement: Existing site procedures and policies are adequate to meet the intent of the DOE Order. 


\subsubsection{Generic Follow-up}

Objective: Analysis program includes considerations of generic corrective actions needed for equipment of the same make and model.

Discussion: The Cog Engineer is responsible for reviewing followup actions for impact to other similar equipment or same type equipment. Any additional action or rework required is identified by the Cog Engineer.

Additional followup of root-cause efforts enhancing future analysis is performed in accordance with existing WMH site procedures.

Improvement: Existing site procedures and policies are adequate to meet the intent of the DOE Order.

\subsection{Modification Work}

Facility modification work, including temporary modifications, is accomplished under the same basic administrative controls as those applied to facility maintenance activities so there is no increase in risk to facility equipment, environment, or personnel because of the modifications work.

\subsubsection{Maintenance Program Interface with Modifications}

Objective: Modifications are performed in accordance with requirements and limitations of applicable procedures, codes, standards, and specifications.

Discussion: Modifications work performed by 222-S Laboratory Maintenance is in conformance with the requirements of WHC-CM-6-1 (HNF-PRO-440), WHC-CM-1-8 (HNF-PRO-069), and applicable maintenance procedures.

Improvement: Existing site procedures and policies are adequate to meet the intent of the DOE Order.

\subsubsection{Temporary Repairs or Temporary Modifications}

Objective: Temporary repairs or modifications are reviewed in accordance with the facility modification program prior to implementation. Temporary repairs or modifications are tracked after completion for consideration of permanent corrective action.

Discussion: Temporary repairs and temporary modifications are controlled per the procedural requirements and tracked by the ICS to completion.

Improvement: Existing site procedures and policies are adequate to meet the intent of the DOE Order. Periodic assessment of the program is performed for compliance to the DOE Order. 


\subsection{Additional Maintenance Management Requirements}

A program is in place to prevent equipment and building damage due to cold weather at any nuclear facility that may be at risk:

\subsubsection{Seasonal Facility Preservation Requirements}

Objective: . Cold weather protection program in place to ensure continued safe facility operation is defined and implemented using approved procedures. Program inciudes criteria for preparation (and suspension), periodic surveillances, and program effectiveness evaluations. Lessons learned are evaluated and appropriate program changes made to prevent recurrence.

Discussion: $\quad$ Seasonal freeze protection at 222-S Laboratory is performed in accordance with a specific freeze protection plan for the facility. A winterization and a summarization program exists for $222-\mathrm{S}$ Laboratory.

222-S Laboratory performs continuing assessments for immediate seasonal preservation requirements. A program for extreme weather conditions is developed specifically to meet the protection requirements of $222-\mathrm{S}$ Laboratory.

Improvement: Existing program ensures the protection of the building from freezing conditions. 


\subsection{DEVIATIONS REQUESTED WITH SUPPORTING RATIONALE}

No deviations from the policy requirements identified by DOE Order 4330.4B (DOE 1994) are requested at this time. 


\subsection{IMPLEMENTATION SCHEDULE}

The following is the schedule of activities that are to be accomplished through the next two years and are shown by the quarter/quarters of the year in which the item will be completed.

\begin{tabular}{|c|c|c|c|c|}
\hline & & 1097 & 98 & 99 \\
\hline & 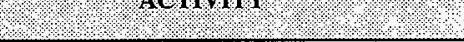 & 12,34 & 12,34 & 12,34 \\
\hline 4.2 & $\begin{array}{l}\text { Maintenance Organization and } \\
\text { Administration }\end{array}$ & & & \\
\hline & $\begin{array}{l}\text { Develop performance indicators and } \\
\text { goals }\end{array}$ & $\mathrm{x}$ & & \\
\hline 4.3 & $\begin{array}{l}\text { Training and Qualification of Maintenance } \\
\text { Personnel }\end{array}$ & & & \\
\hline 4.3 .1 & o Develop a formal training program. & $\mathrm{x}$ & $\mathrm{x} \quad \mathrm{x} \quad \mathrm{x} \quad \mathrm{x}$ & $\mathrm{x} x$ \\
\hline 4.3 .2 & $\begin{array}{l}\text { Develop, define, and track a formal } \\
\text { training program for managers, } \\
\text { supervisors, and technical personnel }\end{array}$ & $\mathrm{x}$ & $\mathrm{x}$ & \\
\hline 4.3 .4 & o Develop OJT program & $\mathrm{x}$ & $\mathrm{x}$ & \\
\hline 4.5 & Types of Maintenance & & & \\
\hline 4.5 .1 & $\begin{array}{l}\text { - Generate a Master Equipment List } \\
\text { (MEL) }\end{array}$ & $\mathrm{x}$ & $\mathrm{x}$ & \\
\hline 4.15 & Management Involvement & & & \\
\hline 4.15 .2 & $\begin{array}{l}\text { - Develop goals, objectives and } \\
\text { performance indicators for the } \\
\text { maintenance organization }\end{array}$ & $\mathrm{x}$ & & \\
\hline 4.16 & Maintenance History and Trending & & & \\
\hline 4.16 .1 & o Complete a Master Equipment List & $\mathrm{x}$ & $x$ & \\
\hline
\end{tabular}




\subsection{BIBLIOGRAPHY}

DOE, 1994, Maintenance Management Program, DOE Order 4330.4B, U.S. Department of Energy, Washington, D.C.

DOE, 1991b, Quality Assurance, DOE Order 5700.6C, U.S. Department of Energy, Washington, D.C.

DOE, 1991a, Accreditation of performance-Based Training for Category A Reactor and Nuclear Facilities, U.S. Department of Energy, Washington, D.C.

DOE, 1993, DOE-RL Hanford Site Hoisting and Rigging Manual, DOE-RL-92-36, U.S. Department of Energy, Richland, Wa. 


\section{DISTRIBUTION}

\section{Number of Copies}

ONSITE

U.S. Department of Energy

\section{Richland Operations Office}

5

F. T. Daniels

S. L. Helmann

B. E. Hill

T. K. Teynor

Public Reading Room
S7-41

S7-41

R3-78

S7-55

$\mathrm{H} 2-53$

H6-10

T6-12

S3-31

T4-55

T6-14

T6-29

T6-14

T3-03

S3-30

A3-88

A3-94

S3-89 